\title{
Celastrol inhibits migration and invasion through blocking the NF-кB pathway in ovarian cancer cells
}

\author{
ZHONGYE WANG ${ }^{*}$, ZHENYUAN ZHAI ${ }^{*}$ and XIULAN DU \\ Department of Obstetrics and Gynecology, Weihai Central Hospital, Weihai, Shandong 264400, P.R. China
}

Received April 7, 2016; Accepted March 10, 2017

DOI: $10.3892 / \mathrm{etm} .2017 .4568$

\begin{abstract}
Metastatic ovarian cancer is a major clinical challenge with poor prognosis and high mortality. Celastrol is a natural compound that has exhibits antiproliferative activity; however, its effects on metastasis-related phenotypes in ovarian cancer models are unclear. In the current study, the anti-invasive activities and associated signaling pathways of celastrol were determined in ovarian cancer cells. Cell proliferation was tested by MTT assay. Cell migration was detected by wound healing and Transwell assays, while cell invasion was detected by a Matrigel-coated Transwell method. In addition, nuclear factor (NF)- $\kappa \mathrm{B}$ and matrix metalloproteinase (MMP) expression was examined by western blotting, and MMP-2/-9 activities were determined by gelatin zymography. At sub-toxic concentrations $(<0.5 \mu \mathrm{M})$, celastrol inhibited migration and invasion in a concentration-dependent manner in SKOV-3 and OVCAR-3 cells. At the molecular level, celastrol blocked the canonical $\mathrm{NF}-\kappa \mathrm{B}$ pathway by inhibiting I $\mathrm{B} \mathrm{B} \alpha$ phosphorylation, and preventing $\mathrm{I} \kappa \mathrm{B} \alpha$ degradation and p65 accumulation. Furthermore, the expression and activity of the NF- $\mathrm{B}$ target protein MMP-9, but not MMP-2, were inhibited by celastrol. Furthermore, celastrol showed no synergistic effect with MG132, an NF- $\kappa$ B inhibitor. In conclusion, celastrol exhibited significant anti-invasive activities in ovarian cancer cells. Such functions may be mediated via NF- $\kappa$ B pathway blockade. The results of this in vitro study strengthen the value of applying celastrol as a potential clinical intervention modality for delaying ovarian cancer metastasis. This, celastrol warrants further preclinical investigation.
\end{abstract}

Correspondence to: Dr Xiulan Du, Department of Obstetrics and Gynecology, Weihai Central Hospital, West 3, Mishan East Road, Wendeng, Weihai, Shandong 264400, P.R. China

E-mail: duxiulanwd@gmail.com

*Contributed equally

Key words: celastrol, nuclear factor- $\kappa \mathrm{B}$, ovarian cancer, migration, invasion

\section{Introduction}

Ovarian cancer is one of the most lethal gynecological malignancies with a high case-to-mortality ratio (1). In 2014, the American Cancer Society reported 21,550 cases of epithelial ovarian carcinoma and 14,600 disease-related mortalities, indicating that $69 \%$ percent of all patients with ovarian carcinoma succumbed to their disease. The high mortality rate of this cancer is largely due to the fact that many patients present with advanced or metastatic disease (2). In addition, conventional treatment strategies such as chemotherapy and radiation are unlikely to reduce the metastatic frequency in ovarian cancer (3).

Nuclear factor (NF)- $\mathrm{kB}$ is a major transcription factor that is essential for the development of inflammation and cancer (4). It is reportedly involved in many physiological functions of cells, including apoptosis, proliferation, invasion and angiogenesis (5). Under normal conditions, NF- $\mathrm{BB}$ is mainly located in the cytoplasm with a heterotrimer complex comprising p50,

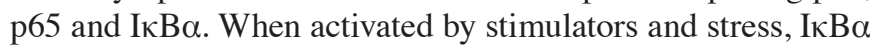
is rapidly phosphorylated, ubiquitinated and degraded by the proteasome. NF- $\mathrm{KB}$ then translocates to the nucleus followed by p65 phosphorylation and binding to specific response elements in the DNA, which subsequently activates target gene expression (5).

NF- $\kappa \mathrm{B}$ controls the expression of an array of genes involved in multiple features of cancer, including proliferation, survival angiogenesis and invasion. In invasion and metastasis, NF- $\mathrm{KB}$ regulates the gene transcription of proteolytic enzymes, cytokines and signaling molecules associated with epithelial-mesenchymal transition (EMT) (6). For example, matrix metalloproteinases (MMPs), such as MMP-2 and -9, have been shown to be typical NF- $\kappa \mathrm{B}$ target proteins that are responsible for extracellular matrix breakdown and cell invasion (7). In addition, NF- $\mathrm{kB}$ serves as a key regulator for EMT-associated proteins such as Snail and Slug (8-10).

Traditional herbal medicines have demonstrated great potential in cancer treatment. Several natural materials used in Chinese medicines, including green tea polyphenols, curcumin and triptolide, have been intensively studied and exhibit antitumor efficacy in preclinical models of various cancer types (11). Some leads are currently in early stage clinical trials for a variety of cancers in combination with other interventions. For example, curcumin shows considerable prevention effects when used before chemotherapy in Phase I 
trials in colon cancer patients (12). One reason for the extensive application of traditional medicine in modern cancer therapy is that, in comparison with chemotherapy, natural agents are less toxic to normal tissues and, therefore, patients maintain tolerance to them (13). Notably, many natural compounds have been found to effectively suppress NF- $\mathrm{NB}$ signaling, providing an experimentally validated molecular explanation for their functional outcomes in tumor cells (14).

Celastrol is a natural triterpene derived from the Chinese plant Thunder God Vine (Tripterygium wilfordii). It is a pleiotropic compound showing antitumor, anti-inflammatory, antihypertensive and antidiabetic activities (15). With regard to cancer treatment, celastrol has been shown to exert considerable cell-killing effects and to shrink xenografted tumors in tissue and animal models of various malignancies including cancers of the prostate (16-18), breast (19), liver $(20,21)$ and lung $(22,23)$. However, the intervention potential of celastrol on the growth, survival and metastatic features of ovarian cancer cells remains largely unknown.

In the current study, the functional role of celastrol in ovarian cancer cell migration and invasion, two key steps in the metastatic cascade, was evaluated. Furthermore, the possible molecular mechanism underlying the effects of celastrol on the cells was investigated.

\section{Materials and methods}

Cell lines. OVCAR-3 and SKOV-3 cells were purchased from ATCC (Manassas, VA, USA). Cells were cultured in Dulbecco's modified Eagle's medium (DMEM; Hyclone; GE Healthcare Life Sciences, Logan, UT, USA) supplemented with $10 \%$ (v/v) heat-inactivated fetal bovine serum (FBS; Hyclone; GE Healthcare Life Sciences), $100 \mathrm{U} / \mathrm{ml}$ penicillin and $100 \mu \mathrm{g} / \mathrm{ml}$ streptomycin (Gibco; Thermo Fisher Scientific, Inc., Waltham, $\mathrm{MA}, \mathrm{USA}$ ), at $37^{\circ} \mathrm{C}$ in a humidified $5 \% \mathrm{CO}_{2}$ incubator. All cells were passaged using $0.05 \%$ trypsin/0.02\% EDTA (Gibco; Thermo Fisher Scientific, Inc.).

Reagents. Celastrol was purchased from Sigma-Aldrich (Merck KGaA, Darmstadt, Germany). The powder was reconstituted in DMSO to generate a stock concentration of $20 \mathrm{mMand}$ was stored at-20 ${ }^{\circ}$ C.3-(4,5-Dimethylthiazol-2-yl)-2,5-diphenyltetrazolium bromide (MTT) and MG132 were also purchased from Sigma-Aldrich (Merck KGaA). Cells were treated with varied concentrations of celastrol $(0.125,0.25,0.5,1$ and $2 \mu \mathrm{M})$ depending on the experiments. To detect NF- $\kappa \mathrm{B}$ activity, cells were pre-treated with MG132 $(0.5 \mu \mathrm{M})$ for $1 \mathrm{~h}$ and then treated with celastrol for $24 \mathrm{~h}$. Matrigel was purchased from BD Biosciences (San Diego, CA, USA). Primary antibodies for western blotting were as follows: Antibodies against

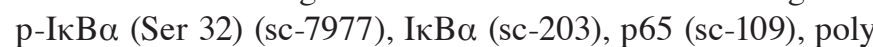
ADP ribose polymerase (PARP) (sc-1562), MMP-2 (sc-53630), MMP-7 (sc-8832) and MMP-9 (sc-21733) were purchased from Santa Cruz Biotechnology, Inc. (Dallas, TX, USA). Anti-actin antibody (A5441) was obtained from Sigma-Aldrich (Merck $\mathrm{KGaA})$.

Cell proliferation assay. Cell growth was measured by MTT assay (24). Briefly, OVCAR-3 and SKOV-3 cells $\left(5 \times 10^{3}\right.$ cells/well) were cultured with serially diluted celastrol
$(0.125,0.25,0.5,1$ and $2 \mu \mathrm{M})$ in 96 -well plates. Control cells were incubated with DMSO in fresh medium. Following incubation for $96 \mathrm{~h}$, the medium was removed and the cells were incubated with $20 \mu \mathrm{l} \mathrm{MTT}$ solution $(5 \mathrm{mg} / \mathrm{ml})$ at $37^{\circ} \mathrm{C}$ for $4 \mathrm{~h}$. The MTT was then removed, and $100 \mu \mathrm{l}$ DMSO was added to each well. After $15 \mathrm{~min}$, the absorbance of each well was measured with a microplate reader (Molecular Devices, LLC, Sunnyvale, CA, USA) at a wavelength of $570 \mathrm{~nm}$. The viable cell number was proportional to the absorbance. All assays were performed in triplicate.

Wound healing assay. Cell motility was determined using a wound-healing scratch assay. Briefly, OVCAR-3 cells were seeded in a 6 -well plate $\left(5 \times 10^{4}\right.$ cells/well) and grown until confluency. The confluent monolayer was scratched using a sterilized $1-\mathrm{ml}$ pipette tip and incubated with celastrol $(0.125$, 0.25 and $0.5 \mu \mathrm{M}$ ) in fresh growth medium for $24 \mathrm{~h}$. The movement of cells to the denuded area was photographed.

Transwell assays. For the migration assay, SKOV-3 cells (5x103/insert) in DMEM with $10 \%$ FBS (Hyclone; GE Healthcare Life Sciences) were seeded into a commercial Transwell insert (membrane pore size, $8 \mu \mathrm{m}$ ) and incubated with celastrol $(0.125,0.25$ and $0.5 \mu \mathrm{M})$. After $24 \mathrm{~h}$, cells that had migrated to the bottom of the filter were stained with crystal violet and counted under a light microscope. For the invasion assay, OVCAR-3 cells were tested using a Transwell insert pre-loaded with Matrigel (BD Biosciences). Inserts were incubated with serum-free DMEM at $37^{\circ} \mathrm{C}$ for $2 \mathrm{~h}$ to allow rehydration of Matrigel. Cells suspended in serum-free DMEM were then loaded onto the top chamber ( $1 \times 10^{4} /$ insert), and celastrol was added to both upper and lower chambers with equal concentrations $(0.125,0.25$ and $0.5 \mu \mathrm{M})$. Complete DMEM with $10 \%$ FBS was used in the lower chamber as a chemo-attractant. After $24 \mathrm{~h}$ of incubation, the Matrigel was removed and the inserts were stained. Invaded cells on the underside of the filter were counted.

Western blotting. The protocol for western blotting was as previously reported (25) with minor modifications. Following treatment with celastrol, OVCAR-3 cells were harvested and lysed in radioimmunoprecipitation assay lysis buffer $[50 \mathrm{mM}$ Tris- $\mathrm{HCl}, \mathrm{pH} 8.0,150 \mathrm{mM} \mathrm{NaCl}, 0.1 \%$ sodium dodecyl sulfate (SDS), $1 \%$ NP-40, $0.25 \%$ sodium deoxycholate and $1 \mathrm{mM}$ EDTA with protease inhibitor cocktail, $1 \mathrm{mM} \mathrm{NaF}$ and $1 \mathrm{mM}$ $\left.\mathrm{Na}_{3} \mathrm{VO}_{4}\right]$ at $4^{\circ} \mathrm{C}$ for $20 \mathrm{~min}$. Whole cell lysates were subjected to protein quantification by Bradford assay. Equal amounts (10 $\mu \mathrm{g} /$ lane) of lysates were resolved by SDS-polyacrylamide gel electrophoresis (SDS-PAGE; Bio-Rad Laboratories, Inc., Hercules, CA, USA) and then electrotransferred to a nitrocellulose membrane (Bio-Rad Laboratories, Inc.). The membrane was probed with primary antibodies against $\mathrm{p}-\mathrm{I} \kappa \mathrm{B} \alpha$ (Ser 32) (1:200), IкB $\alpha$ (1:200), p65 (1:200), PARP (1:200), MMP-2 (1:100), MMP-7 (1:100), MMP-9 (1:100) or Actin $(1: 5,000)$ at $4{ }^{\circ} \mathrm{C}$ overnight, then incubated with horseradish peroxidase (HRP)-conjugated secondary antibodies (anti-mouse IgG1-HRP, ab193651; anti-rabbit IgG1-HRP, ab191866; Abcam, Shanghai, China) with 1:5,000 dilution at room temperature for $1 \mathrm{~h}$, and detected with an enhanced chemiluminescence substrate (Amersham; GE Healthcare Life Sciences). 
Cytosol-nuclei fractionation. To detect the subcellular distribution of NF- $\kappa \mathrm{B}$ proteins, cytoplasmic and nuclear compartments of the cells were prepared as described previously (26). Briefly, following treatment with celastrol, OVCAR-3 cells $\left(3 \times 10^{6}\right)$ were suspended in hypotonic lysis buffer (10 mM HEPES, $5 \mathrm{mM} \mathrm{KCl,} 1 \mathrm{mM} \mathrm{MgCl} 2,1 \mathrm{mM}$ phenylmethylsulfonyl fluoride, $1 \mathrm{mM}$ dithiothreitol and protease inhibitors) and incubated at $4^{\circ} \mathrm{C}$ for $15 \mathrm{~min}$. Nonidet P-40 (10\%) was then added to a final concentration of $0.5 \%$. Immediately after NP-40 addition, samples were vortexed and centrifuged at 13,000 $\mathrm{x}$ g for $1 \mathrm{~min}$, and supernatant (cytosolic extract) was collected. For the precipitation, Laemmli lysis buffer (Santa Cruz Biotechnology, Inc.) was used to reconstitute the pellet followed by ultrasonic homogenization on ice to generate the nuclear extract. Subcellular proteins were quantified by Bradford assay and employed for western blot analysis.

Gelatin zymography. OVCAR-3 cells were treated with celastrol $(0.25$ or $0.5 \mu \mathrm{M})$ for $24 \mathrm{~h}$. Supernatants were collected and loaded on a $10 \%$ SDS-PAGE gel with gelatin $(1 \mathrm{mg} / \mathrm{ml})$. Following electrophoresis, the gels were washed for $15 \mathrm{~min}$ in 2.5\% Triton X-100 and then incubated overnight in the same buffer at room temperature. After washing with deionized water, the gels were incubated for an additional $24 \mathrm{~h}$ at $37^{\circ} \mathrm{C}$ in a calcium-zinc renaturation buffer (1610765; Bio-Rad Laboratories, Inc.). The gel was stained with Coomassie blue R-250. Clear bands appearing at the expected locations for matrix metalloprotease (MMP)-9 and MMP-2 on the basis of molecular weight markers were visualized using a transilluminating densitometer. The number of pixels per band was used to determine the enzyme activity in each group. The zymography experiment was repeated three times with independent samples.

Statistical analysis. All data are expressed as the mean \pm standard deviation (SD). Inter-group analyses were performed using analysis of variance with Prism 5.0 software (GraphPad Software, Inc., La Jolla, CA, USA). P $<0.05$ was considered to indicate a statistically significant difference.

\section{Results}

Anti-proliferative effect of celastrol on ovarian cancer cells. The impact of celastrol on cell proliferation was investigated. SKOV3 and OVCAR-3 ovarian cancer cells were treated with serial concentrations of celastrol and cell proliferation was tested by MTT assay. Celastrol markedly inhibited cell proliferation when concentrations $\geq 1 \mu \mathrm{M}$ were used in the two cell lines, while at $<1 \mu \mathrm{M}$, the drug yielded only modest effects (Fig. 1). In order to exclude the antiproliferative effect of celastrol from its effects on cell migration and invasion, drug concentrations $<1 \mu \mathrm{M}$ were used for subsequent experiments.

Celastrol inhibits ovarian cancer cell migration. The effect of celastrol on cell movement was evaluated by wound-healing scratch assay and Transwell assays. When used at subtoxic concentrations $(0.125-0.5 \mu \mathrm{M})$, celastrol clearly decreased the number of OVCAR-3 cells that moved into the denuded area (Fig. 2A). Consistent with this, in the Transwell migration

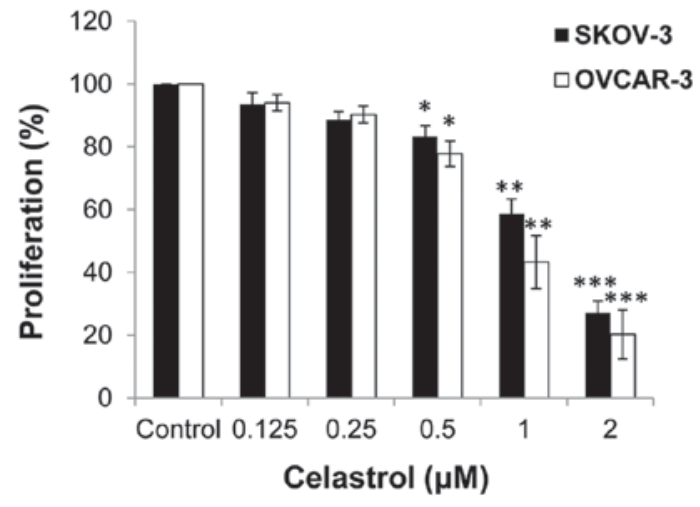

Figure 1. Effect of celastrol on cell proliferation. SKOV-3 and OVCAR-3 cells were seeded into a 96-well plate and treated with various concentrations of celastrol. Cell viability was determined by MTT assay after $96 \mathrm{~h}$ incubation. Results are presented as the mean \pm standard deviation $(n=3)$. ${ }^{*} \mathrm{P}<0.05$, ${ }^{* *} \mathrm{P}<0.005$ and ${ }^{* * *} \mathrm{P}<0.001$ vs. untreated control.

A

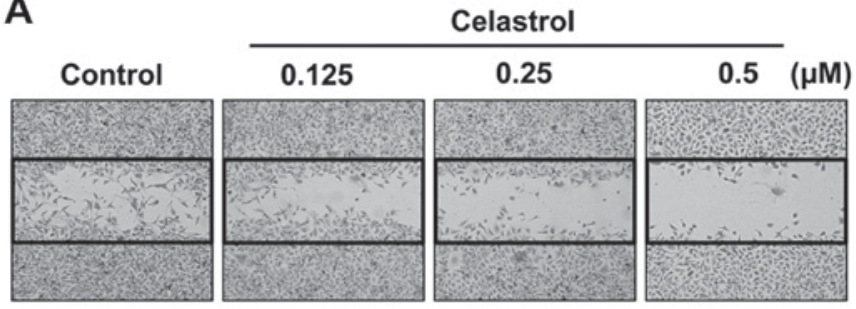

B

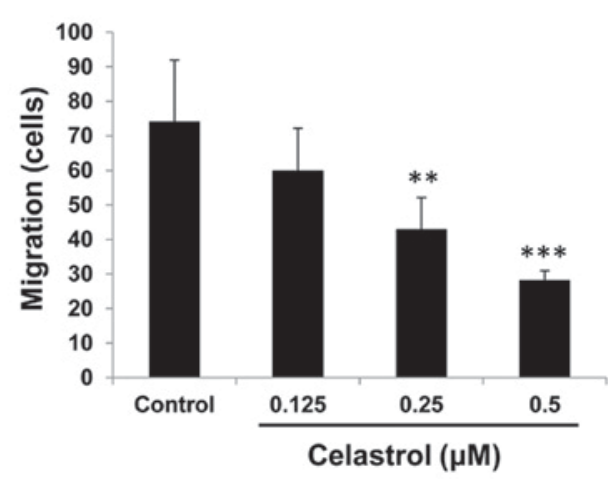

Figure 2. Effect of celastrol on the cell migration of ovarian cancer cells (A) Confluent OVCAR-3 cell monolayers were scratched and treated with celastrol. After $24 \mathrm{~h}$, the migration of cells into the denuded area was visualized. Typical images of cell migration are shown (original magnification, x50). Data are from three independent experiments. (B) SKOV-3 cells were seeded into Transwell inserts $\left(5 \times 10^{3} /\right.$ insert) with or without celastrol. The underside of the filter was stained $24 \mathrm{~h}$ after cell loading. Migrating cells were scored from 10 random fields (original magnification, $x 100$ ). Results are presented as the mean \pm standard deviation $(n=10) .^{* *} \mathrm{P}<0.005$ and ${ }^{* * * *} \mathrm{P}<0.001$ vs. untreated control.

assay, the number of SKOV-3 cells that passed through the Transwell membrane was significantly reduced by celastrol in a concentration-dependent manner (Fig. 2B).

Celastrol suppresses ovarian cancer cell invasion. The effect of celastrol on the invasive capacity of OVCAR-3 cells was investigated. In a Matrigel-coated Transwell assay, celastrol at concentrations of 0.25 and $0.5 \mu \mathrm{M}$ significantly inhibited cell invasion (Fig. 3). The inhibition rates were 39.6 5 5.2 and $51.7 \pm 3.5 \%$ for 0.25 and $0.5 \mu \mathrm{M}$ celastrol, respectively. 


\section{Control}
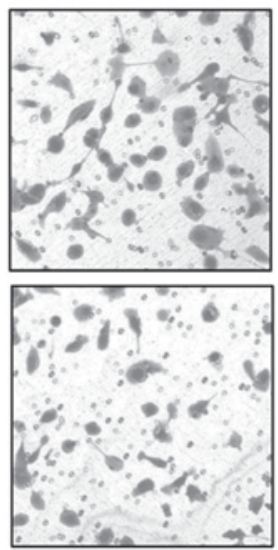

Cel $0.25 \mu \mathrm{M}$
Cel $0.125 \mu \mathrm{M}$
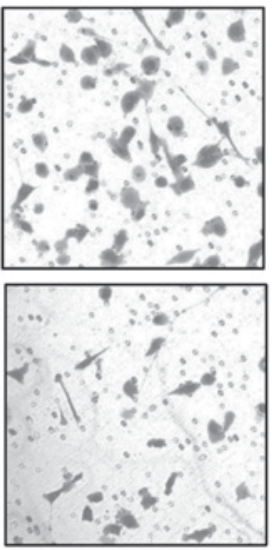

Cel $0.5 \mu \mathrm{M}$

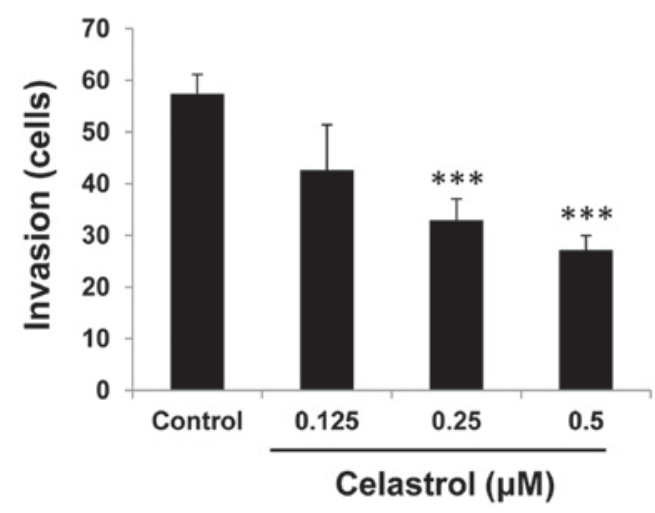

Figure 3. Effect of celastrol on ovarian cancer cell invasion. OVCAR-3 cells were seeded into Matrigel-coated Transwell inserts (1x104/insert) with or without celastrol in the serum-free medium. Complete medium was loaded in the bottom chamber as a chemo-attractant. The underside of the filter was stained $24 \mathrm{~h}$ after cell loading. Invading cells were scored from 8 random fields (original magnification, x100). Representative images are shown. Quantified data are from three independent experiments. Results are presented as the mean \pm standard deviation $(n=6) .{ }^{* * *} \mathrm{P}<0.001$ vs. untreated control. Cel, Celastrol.

Celastrol strongly blocks the $N F-\kappa B$ pathway. To elucidate the molecular mechanisms by which celastrol affects ovarian cancer cells, proteins in the NF-kB pathway were analyzed, since this pathway is indicated to be one of the predominant mechanisms underlying the antitumor efficacy of celastrol (27). As shown in

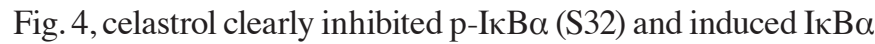
accumulation in the cytosol, and consistent with this, reduced nuclear p65 recruitment in OVCAR-3 cells, suggesting blockade of the canonical NF- $\mathrm{KB}$ pathway. The levels of cytosolic p65 and nuclear I $\mathrm{KB} \alpha$ were undetectable, with or without drug treatment, indicating that celastrol did not affect the translocation of these proteins. Notably, nuclear-specific protein PARP was undetectable in the cytosolic compartment, indicating the precision of the cytosol-nuclei fractionation.

MMP-9 expression and activity are reduced by celastrol. NF- $\mathrm{KB}$ controls the gene expression of many proteolytic enzymes involved in cell invasion and metastasis, such as urokinase-type plasminogen activator and MMP-9 (5). To test whether celastrol impacts the expression of MMPs, three typical MMPs (MMP-2, MMP-7 and MMP-9) were detected in OVCAR-3 cells following

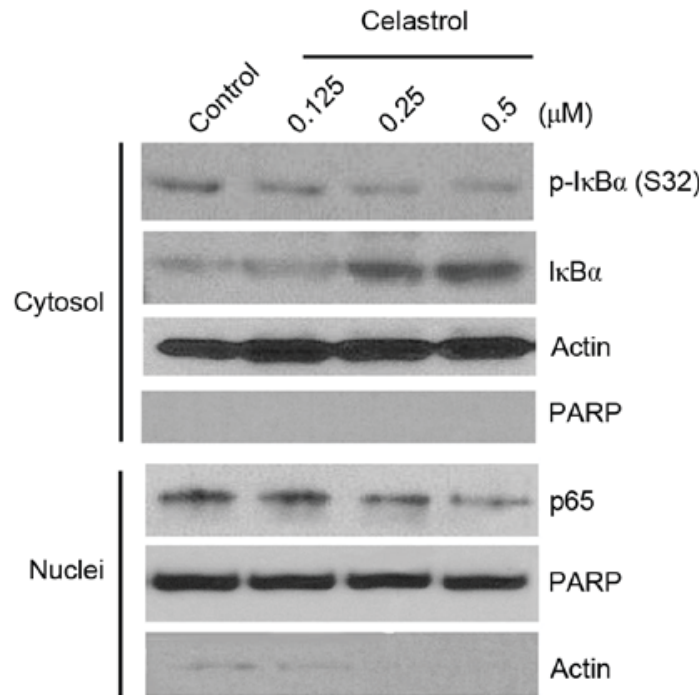

Figure 4. Effect of celastrol on the nuclear factor- $\mathrm{kB}$ pathway. OVCAR-3 cells were treated with celastrol for $6 \mathrm{~h}$. Cytosolic and nuclear extracts were subjected to western blotting with the indicated antibodies. Cytosolic extract was probed with the antibody against I $\mathrm{KB} \alpha$, with actin as a loading control, while the nuclear compartment was detected by an anti-p65 antibody, with PARP as a loading control. PARP, poly ADP ribose polymerase; $\mathrm{p}$, phosphorylated.

A
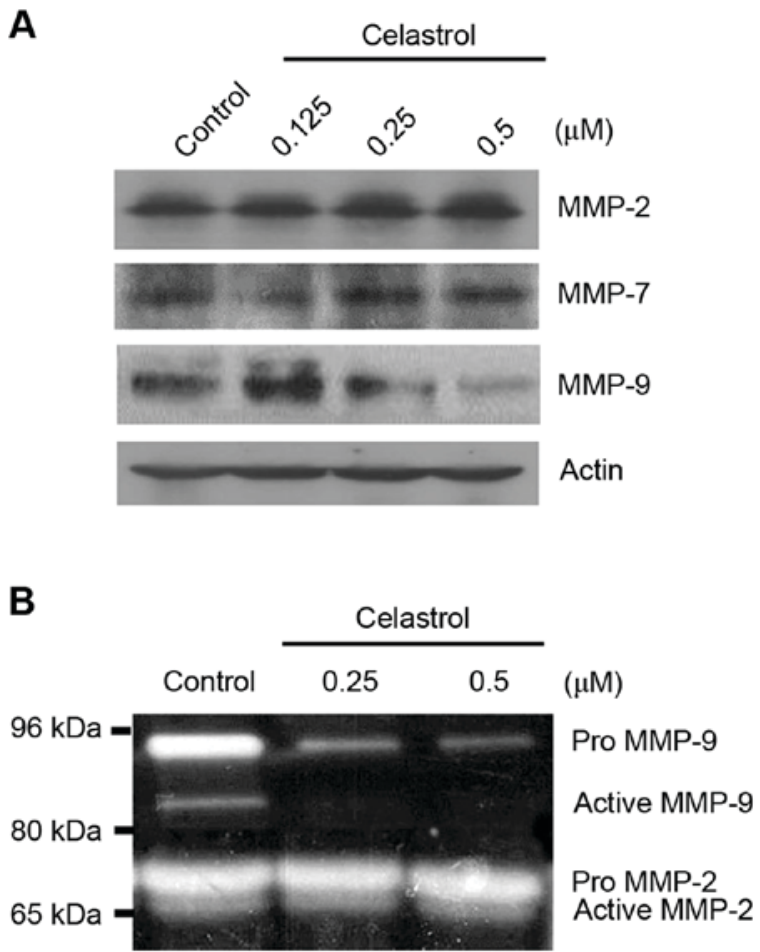

Figure 5. Effect of celastrol on MMP expression and activity. (A) OVCAR-3 cells were treated with celastrol for $24 \mathrm{~h}$. Whole cell lysates were processed for western blotting with primary antibodies against MMP-2, -7 and -9. Actin was used as a loading control. (B) Representative zymographic image showed reduced intensity of gelatin bands associated with active MMP-9 (92 kDa) but not MMP-2 (72 kDa). MMP, matrix metalloproteinase.

celastrol treatment. MMP-9 protein was clearly inhibited by celastrol, particularly at higher concentrations (Fig. 5A). By contrast, no inhibition of MMP-2 and MMP-7 was observed (Fig. 5A). Furthermore, in the zymography assay, the expression 


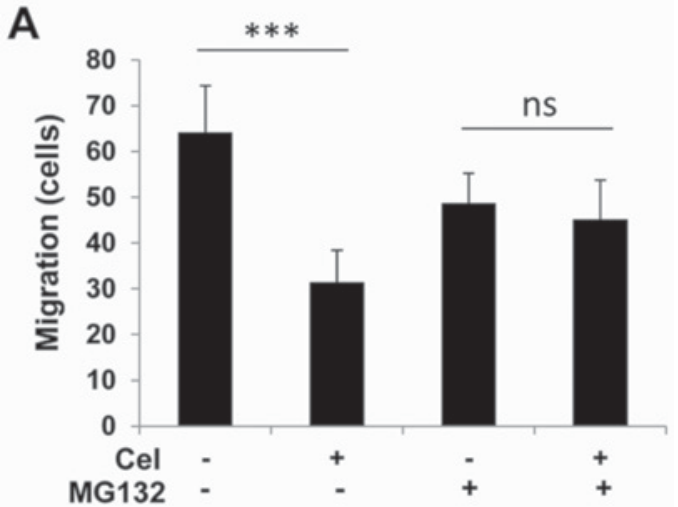

B

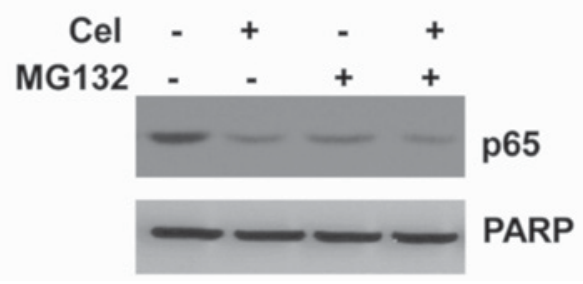

Figure 6. Impact of the NF-кB inhibitor MG132 on celastrol-induced effects. OVCAR-3 cells were pre-treated with MG132 $(0.5 \mu \mathrm{M})$ for $1 \mathrm{~h}$ and then treated with celastrol $(0.5 \mu \mathrm{M})$ for $24 \mathrm{~h}$. (A) Cells were seeded into Transwell inserts $\left(5 \times 10^{3} /\right.$ insert $)$ in triplicate and the filter membrane was stained $24 \mathrm{~h}$ after cell seeding. Migrating cells were scored from 10 random fields (original magnification, $x 100)$. Results are presented as the mean \pm standard deviation $(\mathrm{n}=10) .{ }^{* * *} \mathrm{P}<0.001$ vs. untreated control. ns, not significant. (B) Expression of p65 in the nuclear compartment after subcellular fractionation was detected using western blotting, with PARP as a loading control. PARP, poly ADP ribose polymerase; cel, celastrol; ns, not significant.

of gelatin (the substrate of MMP-2 and MMP-9), was decreased at $92 \mathrm{kDa}$ (for Pro MMP-9) and $83 \mathrm{kDa}$ (for active MMP-9), but not $72 \mathrm{kDa}$ (for Pro MMP-2) and $66 \mathrm{kDa}$ (for active MMP-2) by celastrol treatment, suggesting that celastrol inhibits the proteolytic activity of MMP-9, but not that of MMP-2 (Fig. 5B).

$N F-\kappa B$ pathway inhibitor MG132 attenuates celastrol-induced cell migration and p65 inhibition. In order to investigate whether the mechanism for the inhibition of migration and invasion by celastrol involves $\mathrm{NF}-\kappa \mathrm{B}$, the proteasome inhibitor MG132 was used as an NF- $\mathrm{BB}$ inhibitor; MG132 is widely used as a tool to study NF- $\kappa \mathrm{B}$ signaling and associated molecular mechanisms (28). As shown in Fig. 6A, both celastrol and MG132 inhibited cell migration when applied alone. However, when these two agents were used together, the celastrol-induced suppression was not further increased by MG132; the celastrol-induced movement of tumor cells was attenuated by MG132. Consistently, at the molecular level, MG132 together with celastrol did not show stronger p65 suppression compared with either celastrol or MG132 alone, suggesting that the celastrol-mediated functions proceed via the same pathway as MG132, that is, through NF-kB pathway (Fig. 6B).

\section{Discussion}

Celastrol has been shown to have anti-invasive and antimetastatic activities in preclinical models of prostate cancer (17), breast cancer (19), colon cancer and pancreatic cancer (29). The current study provides new evidence for the inhibitory effect of celastrol on certain functions of ovarian cancer cells. The in vitro data indicate that celastrol may be a suitable candidate for preventing tumor cell migration and invasion in ovarian cancer. Furthermore, such functional consequences are associated with blockade of the NF- $\mathrm{B} / \mathrm{MMP}-9$ pathway, which is widely associated with malignancy and aggressiveness $(30,31)$.

Natural medicines have been studied in cancer management for many years, usually in combination with traditional interventions. Products from the plant Tripterygium wilfordii, including celastrol and triptolide, have exhibited impressive anticancer activities in a variety of cancer models, and therefore are amongst the traditional herb medicines considered to have the most potential in modern cancer therapy (11). For the treatment of ovarian cancer, while very limited studies have focused on celastrol, triptolide, which exhibits similar biological activities to celastrol, has been demonstrated to exert efficacy in preclinical models (32). Ou et al reported that triptolide effectively inhibits ovarian cancer cell proliferation by blocking the HER2/PI3K/Akt/NF- $\mathrm{B}$ pathway (33). In addition, triptolide has been shown to potently inhibit the migration and invasion of ovarian cancer cells, and such suppression is strongly associated with the reduced transcription and translation of several MMPs (34). The results of the present study indicate that celastrol, an analog of triptolide, impairs ovarian cancer cell migration and invasion, and inhibits the NF- $\mathrm{B} / \mathrm{MMP}-9$ pathway; such molecular findings are consistent with previous studies in other cancers $(7,19)$. Together, these findings provide information useful for future studies on these active ingredients from the plant Tripterygium wilfordii, in cancer treatment.

Various molecular mechanisms have been described for the antitumor effects of celastrol. While many signaling pathways are highly associated with survival and apoptosis, $\mathrm{NF}-\kappa \mathrm{B}$ is the predominant pathway that plays a pleiotropic role in controlling multiple cell functions, including proliferation, survival, cell death, invasion and angiogenesis (5). The NF- $\kappa$ B pathway serves as one of the major mechanisms underlying the cancer-killing effects of natural compounds.

In the current study, the results indicated that the NF- $\kappa \mathrm{B}$ pathway may be an important in the functional changes induced by celastrol. In particular, they suggest that celastrol may inhibit the classical NF- $\kappa \mathrm{B}$ pathway by preventing $\mathrm{I} \kappa \mathrm{B} \alpha$ degradation, blocking p65 translocation and suppressing MMP-9 expression downstream of $\mathrm{NF}-\kappa \mathrm{B}$. These results are consistent with those of previous studies $(18,19,27)$, although other studies have suggested different mechanisms for the effects of celastrol on invasiveness $(22,35-38)$. It should be noted that alternative mechanisms to the $\mathrm{NF}-\kappa \mathrm{B}$ pathway are also likely to contribute to the effects of celastrol on migration and invasion in the current models. For example, $\mathrm{Rac} / \mathrm{Rho}$ GTPase is a key player involved in cell skeletal rearrangement and cell polarity, while the Src/FAK axis is a major pathway controlling focal adhesion, cell movement and invasion (39). Notably, celastrol is able to suppress the constitutive phosphorylation of Src kinase at least in multiple myeloma cells (40), suggesting that Src may serve as another potential molecular contributor. Future studies will focus on detailed delineation of the signaling pathways interrupted by celastrol. 
In summary, the results of the present study illustrate the potential of celastrol for impairing tumor invasiveness in ovarian cancer, therefore broadening the possible applications of this natural agent. The results of these in vitro experiments supports the use of celastrol as a potential clinical intervention modality for preventing and delaying ovarian cancer metastasis. Therefore, celastrol warrants further preclinical investigation.

\section{References}

1. Jelovac D and Armstrong DK: Recent progress in the diagnosis and treatment of ovarian cancer. CA Cancer J Clin 61: 183-203, 2011.

2. Naora $\mathrm{H}$ and Montell DJ: Ovarian cancer metastasis: Integrating insights from disparate model organisms. Nat Rev Cancer 5: 355-366, 2005.

3. Bowtell DD, Böhm S, Ahmed AA, Aspuria PJ, Bast RC Jr, Beral V, Berek JS, Birrer MJ, Blagden S, Bookman MA, et al: Rethinking ovarian cancer II: Reducing mortality from high-grade serous ovarian cancer. Nat Rev Cancer 15: 668-679, 2015.

4. Karin M and Greten FR: NF-kappaB: Linking inflammation and immunity to cancer development and progression. Nat Rev Immunol 5: 749-759, 2005.

5. Karin M, Cao Y, Greten FR and Li ZW: NF-kappaB in cancer: From innocent bystander to major culprit. Nat Rev Cancer 2: 301-310, 2002.

6. Min C, Eddy SF, Sherr DH and Sonenshein GE: NF-kappaB and epithelial to mesenchymal transition of cancer. J Cell Biochem 104: 733-744, 2008.

7. Malaponte G, Signorelli SS, Bevelacqua V, Polesel J, Taborelli M, Guarneri C, Fenga C, Umezawa K and Libra M: Increased levels of NF-kB-dependent markers in cancer-associated deep venous thrombosis. PLoS One 10: e0132496, 2015.

8. Wu K and Bonavida B: The activated NF-kappaB-Snail-RKIP circuitry in cancer regulates both the metastatic cascade and resistance to apoptosis by cytotoxic drugs. Crit Rev Immunol 29: 241-254, 2009.

9. Storci G, Sansone P, Mari S, D'Uva G, Tavolari S, Guarnieri T, Taffurelli M, Ceccarelli C, Santini D, Chieco P, et al: TNFalpha up-regulates SLUG via the NF-kappaB/HIF1alpha axis, which imparts breast cancer cells with a stem cell-like phenotype. J Cell Physiol 225: 682-691, 2010.

10. Do SI, Kim JY, Kang SY, Lee JJ, Lee JE, Nam SJ and Cho EY: Expression of TWIST1, Snail, Slug, and NF- $\mathrm{B}$ and methylation of the TWIST1 promoter in mammary phyllodes tumor. Tumour Biol 34: 445-453, 2013.

11. Corson TW and Crews CM: Molecular understanding and modern application of traditional medicines: Triumphs and trials. Cell 130: 769-774, 2007.

12. Johnson JJ and Mukhtar H: Curcumin for chemoprevention of colon cancer. Cancer Lett 255: 170-181, 2007.

13. Sak K: Chemotherapy and dietary phytochemical agents. Chemother Res Pract 2012: 282570, 2012.

14. Li-Weber M: Targeting apoptosis pathways in cancer by Chinese medicine. Cancer Lett 332: 304-312, 2013.

15. Wong KF, Yuan Y and Luk JM: Tripterygium wilfordii bioactive compounds as anticancer and anti-inflammatory agents. Clin Exp Pharmacol Physiol 39: 311-320, 2012.

16. Chiang KC, Tsui KH, Chung LC, Yeh CN, Chen WT, Chang PL and Juang HH: Celastrol blocks interleukin-6 gene expression via downregulation of NF- $\kappa$ B in prostate carcinoma cells. PLoS One 9: e93151, 2014.

17. Dai Y, Desano J, Tang W, Meng X, Meng Y, Burstein E, Lawrence TS and Xu L: Natural proteasome inhibitor celastrol suppresses androgen-independent prostate cancer progression by modulating apoptotic proteins and NF-kappaB. PLoS One 5: e14153, 2010

18. Shao L, Zhou Z, Cai Y, Castro P, Dakhov O, Shi P, Bai Y, Ji H, Shen W and Wang J: Celastrol suppresses tumor cell growth through targeting an AR-ERG-NF- $\kappa$ B pathway in TMPRSS2/ERG fusion gene expressing prostate cancer. PLoS One 8: e58391, 2013.

19. Kim Y, Kang H, Jang SW and Ko J: Celastrol inhibits breast cancer cell invasion via suppression of NF-kB-mediated matrix metalloproteinase-9 expression. Cell Physiol Biochem 28: 175-184, 2011.

20. Li PP, He W, Yuan PF, Song SS, Lu JT and Wei W: Celastrol induces mitochondria-mediated apoptosis in hepatocellular carcinoma Bel-7402 cells. Am J Chin Med 43: 137-148, 2015.
21. Rajendran P,LiF, Shanmugam MK, Kannaiyan R, Goh JN, Wong KF, Wang W, Khin E, Tergaonkar V,Kumar AP, et al: Celastrol suppresses growth and induces apoptosis of human hepatocellular carcinoma through the modulation of STAT3/JAK2 signaling cascade in vitro and in vivo. Cancer Prev Res (Phila) 5: 631-643, 2012.

22. Wang GZ, Liu YQ, Cheng X and Zhou GB: Celastrol induces proteasomal degradation of FANCD2 to sensitize lung cancer cells to DNA crosslinking agents. Cancer Sci 106: 902-908, 2015.

23. Fan XX, Li N, Wu JL, Zhou YL, He JX, Liu L and Leung EL: Celastrol induces apoptosis in gefitinib-resistant non-small cell lung cancer cells via caspases-dependent pathways and Hsp90 client protein degradation. Molecules 19: 3508-3522, 2014.

24. Li HY, Zhang J, Sun LL, Li BH, Gao HL, Xie T, Zhang N and Ye ZM: Celastrol induces apoptosis and autophagy via the ROS/JNK signaling pathway in human osteosarcoma cells: An in vitro and in vivo study. Cell Death Dis 6: e1604, 2015.

25. Ling C, Wang Y, Feng YL, Zhang YN, Li J, Hu XR, Wang LN, Zhong MF, Zhai XF, Zolotukhin I, et al: Prevalence of neutralizing antibodies against liver-tropic adeno-associated virus serotype vectors in 100 healthy Chinese and its potential relation to body constitutions. J Integr Med 13: 341-346, 2015.

26. Bolshakova A, Magnusson KE, Pinaev G and Petukhova O: Functional compartmentalisation of NF-kB-associated proteins in A431 cells. Cell Biol Int 37: 387-396, 2013.

27. Ni H, Zhao W, Kong X, Li H and Ouyang J: NF-kappa B modulation is involved in celastrol induced human multiple myeloma cell apoptosis. PLoS One 9: e95846, 2014.

28. Zanotto-Filho A, Braganhol E, Battastini AM and Moreira JC: Proteasome inhibitor MG132 induces selective apoptosis in glioblastoma cells through inhibition of PI3K/Akt and NFkappaB pathways, mitochondrial dysfunction and activation of $\mathrm{p} 38-\mathrm{JNK} 1 / 2$ signaling. Invest New Drugs 30: 2252-2262, 2012.

29. Yadav VR, Sung B, Prasad S, Kannappan R, Cho SG, Liu M, Chaturvedi MM and Aggarwal BB: Celastrol suppresses invasion of colon and pancreatic cancer cells through the downregulation of expression of CXCR4 chemokine receptor. J Mol Med (Berl) 88: 1243-1253, 2010.

30. Jiang L, Wu J, Yang Y, Liu L, Song L, Li J and Li M: Bmi-1 promotes the aggressiveness of glioma via activating the NF-kappaB/MMP-9 signaling pathway. BMC Cancer 12: 406, 2012.

31. Jin J, Shen X, Chen L, Bao LW and Zhu LM: TMPRSS4 promotes invasiveness of human gastric cancer cells through activation of NF-кB/MMP-9 signaling. Biomed Pharmacother 77: 30-36, 2016.

32. Liu Z, Ma L and Zhou GB: The main anticancer bullets of the Chinese medicinal herb, thunder god vine. Molecules 16: 5283-5297, 2011.

33. Ou CC, Chen YW, Hsu SC, Sytwu HK, Loh SH, Li JW and Liu JY: Triptolide transcriptionally represses HER2 in ovarian cancer cells by targeting NF- $\kappa$ B. Evid Based Complement Alternat Med 2012: 350239, 2012.

34. Zhao H, Yang Z, Wang X, Zhang X, Wang M, Wang Y, Mei Q and Wang Z: Triptolide inhibits ovarian cancer cell invasion by repression of matrix metalloproteinase 7 and 19 and upregulation of E-cadherin. Exp Mol Med 44: 633-641, 2012.

35. Lee JH, Won YS, Park KH, Lee MK, Tachibana H, Yamada K and Seo KI: Celastrol inhibits growth and induces apoptotic cell death in melanoma cells via the activation ROS-dependent mitochondrial pathway and the suppression of PI3K/AKT signaling. Apoptosis 17: 1275-1286, 2012.

36. Kang H, Lee M and Jang SW: Celastrol inhibits TGF- $\beta 1$-induced epithelial-mesenchymal transition by inhibiting Snail and regulating E-cadherin expression. Biochem Biophys Res Commun 437: 550-556, 2013.

37. Chakravarthy R, Clemens MJ, Pirianov G, Perdios N, Mudan S, Cartwright JE and Elia A: Role of the eIF4E binding protein 4E-BP1 in regulation of the sensitivity of human pancreatic cancer cells to TRAIL and celastrol-induced apoptosis. Biol Cell 105: 414-429, 2013.

38. Lee HW, Jang KS, Choi HJ, Jo A, Cheong JH and Chun KH: Celastrol inhibits gastric cancer growth by induction of apoptosis and autophagy. BMB Rep 47: 697-702, 2014.

39. Friedl $P$ and Wolf K: Tumour-cell invasion and migration: Diversity and escape mechanisms. Nat Rev Cancer 3: 362-374, 2003.

40. Kannaiyan R, Hay HS, Rajendran P, Li F, Shanmugam MK, Vali S, Abbasi T, Kapoor S, Sharma A, Kumar AP, et al: Celastrol inhibits proliferation and induces chemosensitization through down-regulation of NF- $\mathrm{KB}$ and STAT3 regulated gene products in multiple myeloma cells. Br J Pharmacol 164: 1506-1521, 2011. 